\title{
Assessment of soil-structure interaction on a 51-story building from the spectral ratio of earthquake recordings
}

\author{
Kun-Sung Liu $^{\mathrm{a}}$ \\ Department of Civil Engineering \& Hazard Mitigation Research Center, Kao Yuan University, \\ Kaohsiung City 82151, Taiwan
}

\begin{abstract}
The soil-structure interaction (SSI) can significantly alter the characteristics of recorded motions in buildings. The ratio of Fourier amplitude spectrum of the top-story accelerations to that of the foundation accelerations permits the identification of the natural frequency of the fixed-base building. In this study, records of the Chi-Chi earthquake and the 1226 Hengchun earthquake doublet from the structural array in a 51-story highrise building are used to obtain the dynamic characteristics of the buildings by the transfer function (TF) method. As a result, the acceleration amplification of seismic excitation on the $47^{\text {th }}$ storey of buildings is 4.24, in the horizontal component, from the Chi-Chi earthquake data greater than those of the 1226 Hengchun earthquake doublet with a value of 2.82 and 2.06, respectively. In addition, from the spectral ratio of the accelerations $\left(47^{\text {th }}\right.$ floor/basement), together with the Fourier Amplitude Spectrum (FAS) of the $47^{\text {th }}$ floor and basement accelerations, it is noted that the peaks of the $47^{\text {th }}$ floor FAS and the spectral ratio appear to coincide with each other from the records of 1226 Hengchun earthquake doublet, suggesting that there is no significant SSI effects in both the longitudinal and transverse directions.
\end{abstract}

\section{Introduction}

Taiwan is located in the Circum-Pacific seismic belt. The Philippine Sea plate and the Eurasian plate collide with each other around Taiwan. Therefore, it is not surprising that large earthquakes have repeatedly hit the Taiwan [1]. Safeguarding life and property from destructive effects of earthquakes is a major concern of the people there. Since the most widespread damaging effects of earthquakes are caused by strong ground shaking, effective reduction of life and property losses from strong earthquakes requires conscientious application of earthquake resistant building codes and implementation of appropriate retrofit measures. Ideally, implementation of these mitigation measures should be based on instrumental recordings of strong earthquakes, for such data are crucial for improving earthquake resistant design of buildings [2]. The inclusion of SSI phenomena in the seismic analysis and design of structures has been addressed in seismic code provisions, including the FEMA450 document [3].

The effects of SSI on the seismic response of structures had been seriously taken into account since the 1971 SanFernando earthquake and the beginning of nuclear plant construction in the earthquake-prone California. In the 1980s and 1990s, many studies investigated the effects of SSI on

\footnotetext{
${ }^{a}$ Corresponding author : lk.sung99@msa.hinet.net
} 
special structures [4]. Two schemes of SSI are widely recognized for structures founded on or in soils: inertial and kinematic interaction. Inertial interaction results from inertia forces produced by seismic accelerations of the structure. Inertia forces increase the base shear and overturning moments acting on the foundation, resulting in relative displacements between the free field and foundation [3]. Kinematic interaction, on the other hand, occurs due to the inability of the relatively rigid foundation to conform to the ground motion, causing deviation of the foundation motion from the free-field motion. This is particularly accentuated by incoherent ground motion, wave inclination, and foundation embedment effects [5]. A detailed discussion on SSI effects and analysis techniques is presented by [6].

In general, SSI can decrease the base shear, lateral forces, and overturning moments experienced by a structure during earthquakes. However, it increases lateral displacements and secondary forces associated with P-delta effects [7]. Therefore, SSI effects should be considered during the design process [3]. Aviles and Perez-Rocha [8] investigated site effects and SSI during the Mexico earthquake of 1985. They found that interaction effects were larger for tall and slender structures than for short and squat structures of the same period, and these effects decreased as the foundation depth increased. Crouse and Ramirez [9] identified SSI effects and nonlinear site response as the main reasons for the differences observed in three sets of earthquake records for two buildings in the Jensen filtration plant during the Northridge main shock and aftershock motions.

Full-scale monitoring can provide valuable data for realistic evaluation of the dynamic behaviors of tall buildings under earthquake excitations. Analyses of records obtained in buildings during strong earthquakes and ambient vibrations from building have shown the natural frequencies and damping ratio may vary with increasing amplitude of shaking [10-17]. At present reliable field measurements of earthquake effects on tall buildings are still limited [3]. Fortunately, the Central Weather Bureau (CWB) of Taiwan has installed 60 digital strong-motion array systems in buildings and other structures for engineering and scientific purposes since 1992, as part of its Taiwan Strong Motion Instrumentation Program (TSMIP) [18]. It is remarkable that these digital strong-motion arrays have capabilities to record building responses not only due to strong motions but also weak ambient vibrations, owing to a flexible gain selection of the amplifier-filter unit at 1, 10, or 100 [2].

In this study, seismic data recorded in the structural array of a 51-story highrise building in Kaohsiung City are analyzed with several vibration parameters, including its transfer functions and natural frequencies. In addition, the spectral ratio of the accelerations ( $47^{\text {th }}$ floor / basement), together with the Fourier Amplitude Spectrum (FAS) of the $47^{\text {th }}$ floor and basement accelerations excited by the M7.6 Chi-Chi earthquake and the 1226 Hengchun earthquake doublet, are used to assess the SSI effects in both the longitudinal and transverse directions.

\section{Seismic data}

The KBA0 Building is located in Kaohsiung. The building has 51 stories with a total height of 222.1 $\mathrm{m}$ at the roof, as shown in Figure 1. A typical floor plan of the KBA0 Building has a rectangular shape, with a length of $42.5 \mathrm{~m}$ in the NS (i.e. $\mathrm{x}$-x or longitudinal) direction and a width of $34.5 \mathrm{~m}$ in the EW (i.e. $y$-y or transverse) direction. A total of 26 accelerometers are placed at the basement, $1^{\text {st }}, 15^{\text {th }}, 30^{\text {th }}$ and $47^{\text {th }}$ floor. These floors are at height of $-19.5 \mathrm{~m}, 0.0 \mathrm{~m}, 57.6 \mathrm{~m}, 119.2 \mathrm{~m}$, and $191.7 \mathrm{~m}$ relative to the ground surface, respectively (Figure 1).

A major earthquake of $M_{\mathrm{w}}$ magnitude 7.6 took place in central Taiwan at 17:47:16 UT of 20 September 1999. The epicenter was located near the town of Chi-Chi, after which the event was named. This was the largest inland earthquake to strike Taiwan in the twentieth century. The CWB located its epicenter at $120.82^{\circ} \mathrm{E}$ and $23.85^{\circ} \mathrm{N}$, with a focal depth of $8 \mathrm{~km}$ [1]. In addition, on 26 December 2006, two closely linked earthquakes, both ML 7.0, occurred only 8 minutes apart at 12:26:21 and 12:34:15 UT, respectively, in southwestern offshore of Taiwan near Pingtung. The epicenters of three earthquakes and location of the KBA0 building array station, as shown in Figure 2 and given in Table 1, were selected for this study. Records of the Chi-Chi earthquake and the 1226 Hengchun earthquake doublet from the structural array in the KBA0 Building are shown in Figures 3, 
4 , and 5, respectively. The accelerograms of channel number 1, 4, 7, 10, 13, 15, 17, 19, 21 and 24 are plotted for the accelerometers installed in the NS component and channel number 2, 5, 8, 11, 14, 16, 18, 20, 22 and 25 are those in the EW component as well as channel number 3, 6, 9, 12, 23 and 26 are those in the UD component. The largest peak acceleration of $101 \mathrm{~cm} / \mathrm{sec}^{2}$ was recorded in Channel 21 , located at the $47^{\text {th }}$ floor of the KBA0 Building as shown in Figure 3.

Table 1. The earthquake parameters used in this study.

\begin{tabular}{|c|c|c|c|c|c|c|c|c|c|c|c|}
\hline \multirow{2}{*}{ No } & \multirow{2}{*}{ Date } & \multirow{2}{*}{$\begin{array}{l}\text { Time } \\
\text { (UTC) }\end{array}$} & \multirow{2}{*}{$\begin{array}{l}\text { Lat. } \\
(\mathrm{N})\end{array}$} & \multirow{2}{*}{$\begin{array}{l}\text { Lon. } \\
\text { (E) }\end{array}$} & \multirow{2}{*}{$\begin{array}{l}\text { Depth } \\
(\mathrm{km})\end{array}$} & \multicolumn{3}{|c|}{ Peak Acc (1F) } & \multirow{2}{*}{$\mathrm{M}_{\mathrm{L}}$} & \multirow{2}{*}{$\mathrm{M}_{\mathrm{w}}$} & \multirow{2}{*}{$\begin{array}{c}\text { Epicentral } \\
\text { Distance }(\mathrm{km})\end{array}$} \\
\hline & & & & & & $\mathrm{X}(\mathrm{gal})$ & $\mathrm{Y}(\mathrm{gal})$ & $Z$ (gal) & & & \\
\hline 1 & $1999 / 09 / 20$ & $17: 47: 15.85$ & 23.853 & 120.816 & 08.00 & 20.9 . & 24.1 & 12.0 & 7.30 & 7.60 & 144.2 \\
\hline 2 & $2006 / 12 / 26$ & $12: 26: 21.00$ & 21.687 & 120.555 & 44.11 & 17.7 & 19.2 & 18.2 & 6.96 & 7.00 & 108.8 \\
\hline 3 & $2006 / 12 / 26$ & 12:34:15.13 & 21.970 & 120.420 & 50.22 & 36.3 & 40.5 & 37.8 & 6.99 & 6.90 & 75.3 \\
\hline
\end{tabular}

Remark: The moment magnitude $\left(\mathrm{M}_{\mathrm{w}}\right)$ adopted from the Harvard CMT.

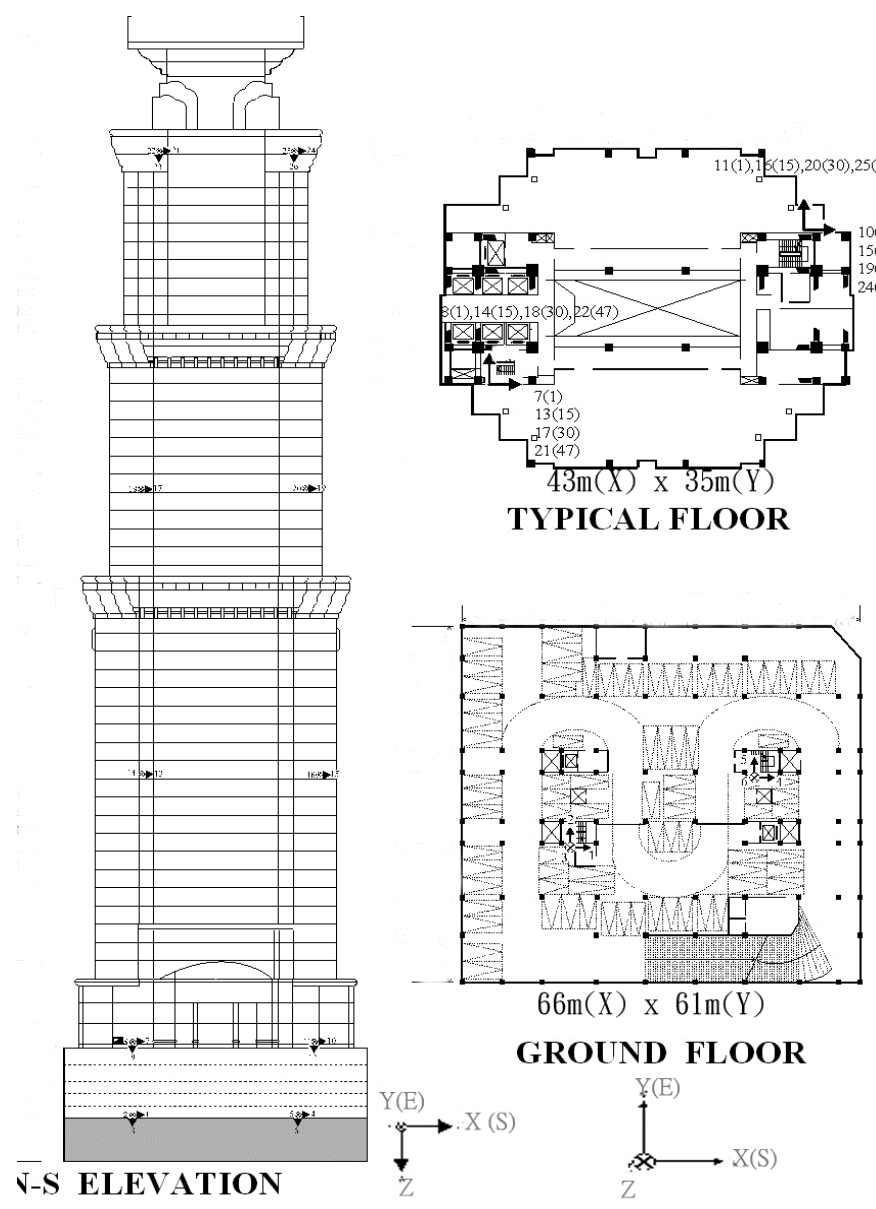

Figure 1. Configurations of the KBA0 Building. Left: NS elevation profile; Top right: a typical floor plan; Lower right: the ground floor plans. The accelerometer components are indicated by arrows. 


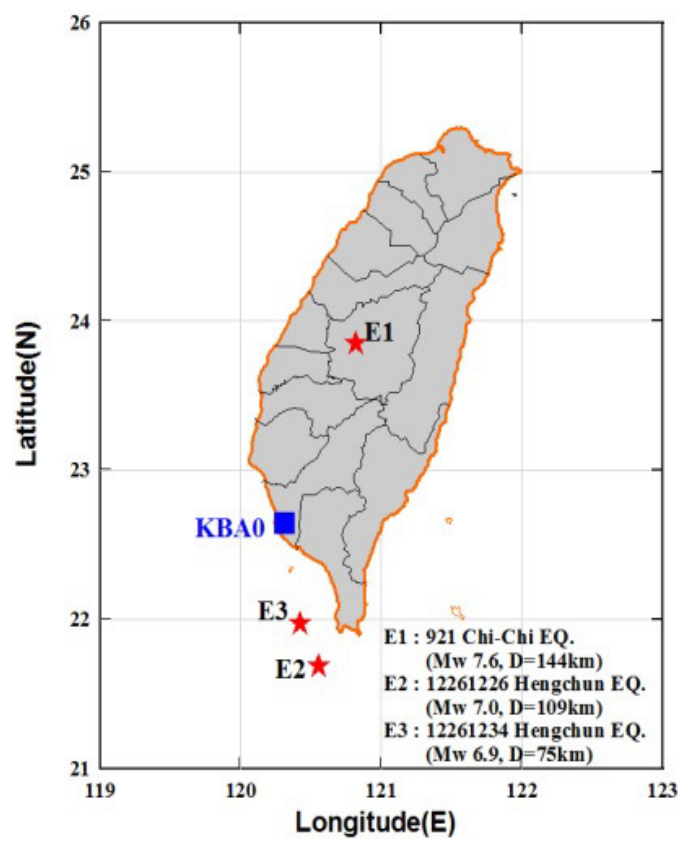

Figure 2. Location of the KBA0 building array station and the three epicenters of earthquakes used in this study.

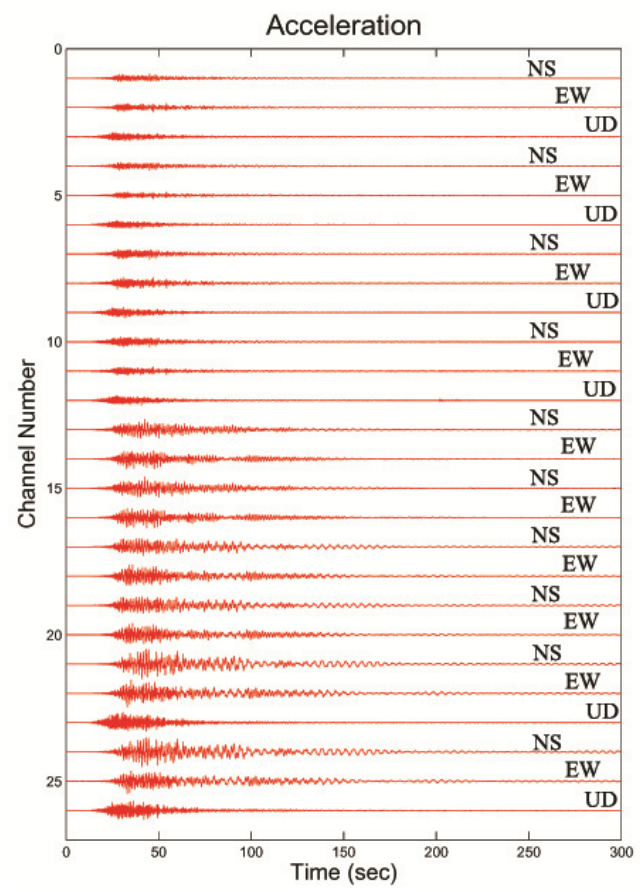

Figure 4. Acceleration time histories of the Hengchun Mw7.0 earthquake, as recorded by the structural array in the KBA0 Building.

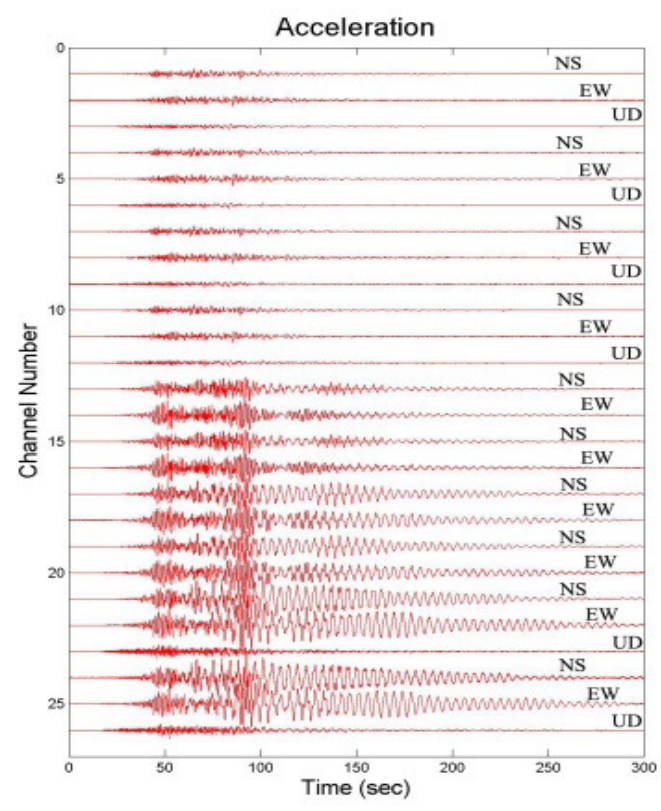

Figure 3. Acceleration time histories of the Chi-Chi earthquake, as recorded by the structural array in the KBA0 Building.

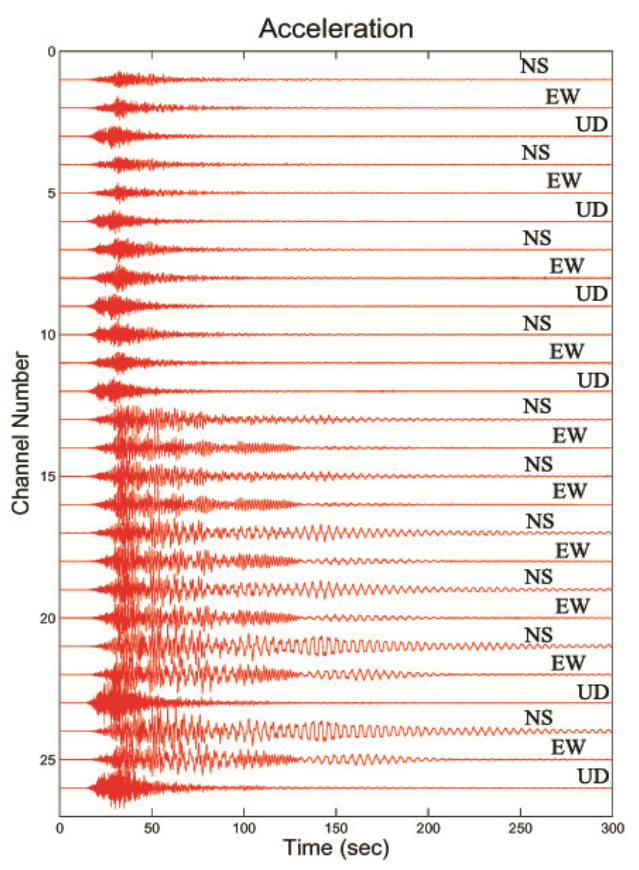

Figure 5. Acceleration time histories of the Hengchun Mw6.9 earthquake, as recorded by the structural array in the KBA0 Building. 


\section{Methodology}

\subsection{Parameters of vibration of the KBAO building}

The measured acceleration data are used to obtain the dynamic characteristics of the buildings. Different sets of modal parameters can be determined from the recorded time histories by several system identification methods, either in frequency domain or time domain. Most commonly used methods are based in frequency domain [19]. In order to identify the natural frequencies of the KBA0 Building, the transfer function (TF) method are used. Details of the TF method can be found in [2022], respectively.

\subsection{Identification of soil-structure interaction in the KBAO building}

The soil-structure interaction (SSI) can significantly alter the characteristics of recorded motions in buildings. The dominant frequency of a building subject to SSI will be smaller than that of a fixedbase building. The ratio of Fourier amplitude spectrum of the top-story accelerations to that of the foundation accelerations permits the identification of the natural frequency of the fixed-base building $[13,23]$.

\section{Results and discussion}

\subsection{Naturaltural frequencies of vibration of the KBAO building}

In the present study, only the first five modes of the building response are considered since higher modes are of little significance in overall building responses [24]. In the following the recorded data in the KBA0 Building from three earthquakes are used to identify the natural frequencies of the $1^{\text {st }}, 2^{\text {nd }}$, $3^{\text {rd }}, 4^{\text {th }}$, and $5^{\text {th }}$ modes of vibration in the longitudinal and transverse directions.

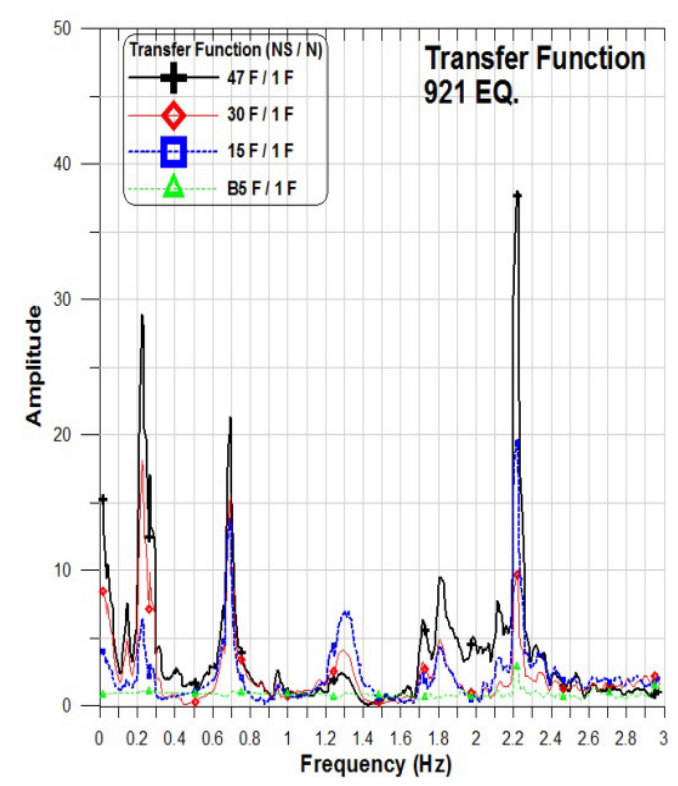

Figure 6. Transfer functions of the KBA0 Building at the north-side in longitudinal direction from the ChiChi earthquake.

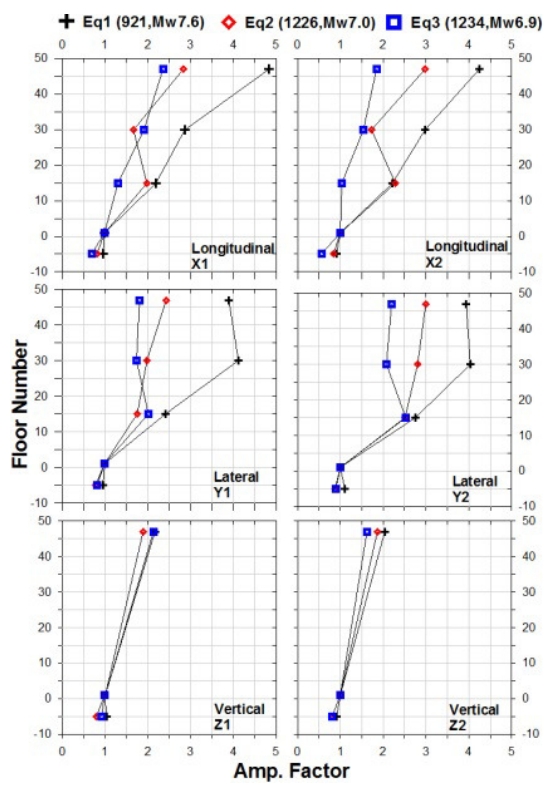

Figure 7. Acceleration amplification of seismic excitation on the different story of KBA0 building. The top, middle and bottom panels in Figure 7 are shown the longitudinal, lateral, and vertical direction, 
respectively.

The natural frequencies of the first five translational modes in each direction evaluated by using the TF method from the observed acceleration data are summarized in Table 2. Figures 6 show the longitudinal transfer functions in the frequency domain as obtained from the Chi-Chi earthquake data by the north-side sensors in the KBA0 Building. By examining the observed transfer functions, the natural frequencies of the $1^{\text {st }}, 2^{\text {nd }}, 3^{\text {rd }} 4^{\text {th }}$, and $5^{\text {th }}$ longitudinal modes of the KBA0 Building are found to be $0.238,0.697,1.284,1.834$ and $2.207 \mathrm{~Hz}$, respectively. Likewise, the corresponding results for the transverse component are $0.220,0.715,1.290,1.797$, and $2.293 \mathrm{~Hz}$, respectively.

Taking the KBA0 Building as a steel structure with eccentrically braced frame, the corresponding fundamental mode period according to the building code can be calculated as follows [25]:

$$
T=0.070 h_{n}^{3 / 4}
$$

Where $h_{n}$ is the height of building from the ground. The calculated natural frequencies for the first five modes are $0.248,0.745,1.242,1.738$, and $2.235 \mathrm{~Hz}$, respectively. It is found that these frequencies conducted from the code formula are closer to those identified from actual data.

In addition, the building array with 26-channel accelerograms recorded from the three earthquakes has been analyzed to study the acceleration amplification of seismic excitation on the 47 story of KBA0 building. The results as shown in Figure 7 show the amplification factor is 4.24 , in the horizontal component, from the Chi-Chi earthquake data greater than those of the 1226 Hengchun earthquake doublet with a value of 2.82 and 2.06 , respectively.

Table 2. Observed modal frequencies $f(\mathrm{~Hz})$ in the longitudinal (L) directions and transverse (T) directions of the KBA0 Building.

\begin{tabular}{|c|c|c|c|c|c|}
\hline Earthquake & Mode & $\begin{array}{c}\text { Longitudinal (L) } \\
\text { X1(Hz) }\end{array}$ & $\begin{array}{c}\text { Longitudinal (L) } \\
\text { X2(Hz) }\end{array}$ & $\begin{array}{c}\text { Transverse (T) } \\
\text { Y1(Hz) }\end{array}$ & $\begin{array}{c}\text { Transverse (T) } \\
\text { Y2(Hz) }\end{array}$ \\
\hline EQ1 & $f_{1}$ & 0.238 & 0.238 & 0.220 & 0.220 \\
& $f_{2}$ & 0.697 & 0.697 & 0.715 & 0.715 \\
& $f_{3}$ & 1.284 & 1.290 & 1.290 & 1.290 \\
& $f_{4}$ & 1.834 & 1.834 & 1.797 & 1.797 \\
& $f_{5}$ & 2.207 & 2.201 & 2.293 & 2.293 \\
\hline EQ2 & $f_{1}$ & 0.238 & 0.238 & 0.232 & 0.232 \\
& $f_{2}$ & 0.702 & 0.702 & 0.702 & 0.702 \\
& $f_{3}$ & 1.270 & 1.270 & 1.331 & 1.331 \\
& $f_{4}$ & 1.752 & 1.752 & 1.752 & 1.752 \\
& $f_{5}$ & 2.069 & 2.069 & 2.191 & 2.191 \\
\hline EQ3 & $f_{1}$ & 0.238 & 0.232 & 0.226 & 0.226 \\
& $f_{2}$ & 0.696 & 0.696 & 0.708 & 0.708 \\
& $f_{3}$ & 1.276 & 1.276 & 1.294 & 1.294 \\
& $f_{4}$ & 1.794 & 1.794 & 1.825 & 1.825 \\
& $f_{5}$ & 2.045 & 2.045 & 2.197 & 2.197 \\
\hline
\end{tabular}

\subsection{Identification of soil-structure interaction in the KBAO building}

It has been demonstrated that the fundamental frequency of the building may vary with the intensity of excitation force. The change in frequency may be attributed to one or more of the following causes: 1 . Change in building effective stiffness, which could be due to the cracking of RC sections on the tension side and/or the disengagement of stiffness-contributing nonstructural elements; 2. Change of foundation stiffness due to softening in the soil at larger strains and the resulting effect of soilstructure interaction; and 3. Structural damage [14-15,17].

In order to understand the characteristics of response spectra between the three earthquakes and torsional predominant frequency, the Fourier amplitude spectrum of the basement, $1^{\text {st }}, 15^{\text {th }}, 30^{\text {th }}$ and $47^{\text {th }}$ floor in the longitudinal direction (X1) are plot in the Figure 8. The top, middle and bottom panels 
in Figure 8 are shown the chi-chi earthquake, Hengchun M7.0 earthquake, and Hengchun M6.9 earthquake, respectively. In addition, the Fourier amplitude spectra of the three earthquakes in the $47^{\text {th }}$ floor are plot in the Figure 9. The top, middle and bottom panels in Figure 9 are shown the longitudinal, lateral, and vertical direction, respectively. From the Figures 8 and 9, we can find the following results: (1) it shows that amplitude spectrum decrease with increasing frequency, especially for that of the chi-chi earthquake. It probably due to that the difference of vary for frequency content decay with distance. (2) The high story (47F) has high Fourier spectrum while the frequency is lower than $0.8 \mathrm{~Hz}$ among the three earthquakes, especially for the horizontal component and chi-chi earthquake. (3) The torsional predominant frequency is $0.960 \mathrm{~Hz}$ after comparing the recording from the different site in the transverse direction of same floor.

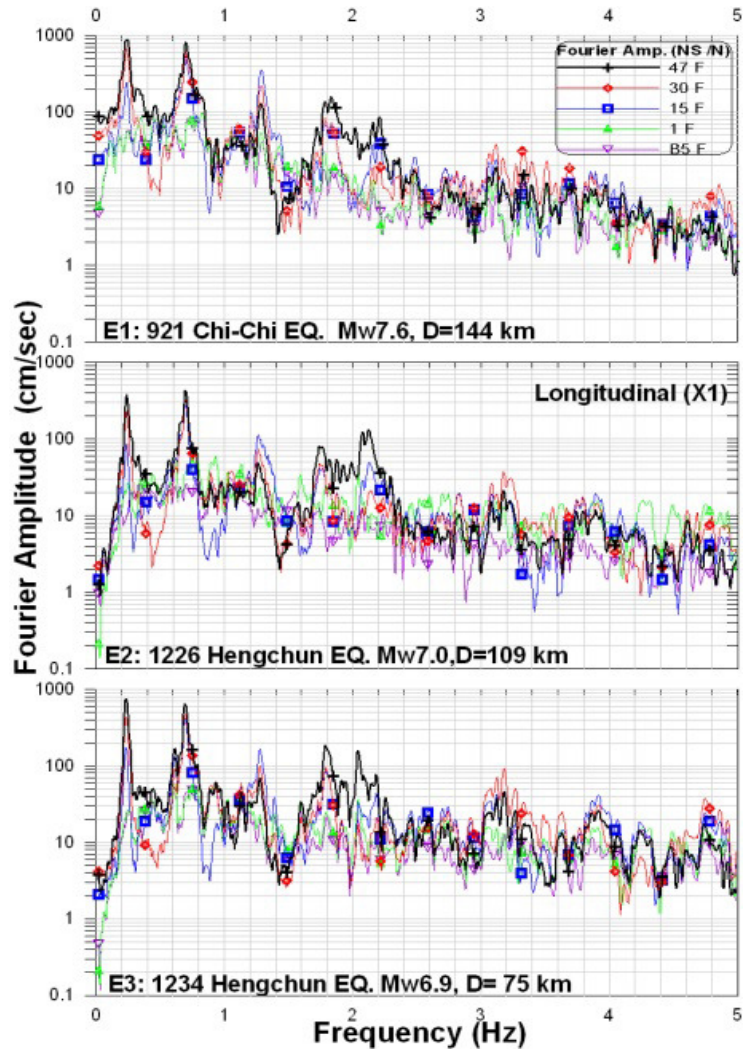

Figure 8. Fourier amplitude spectrum of the basement, $1^{\text {st }}, 15^{\text {th }}, 30^{\text {th }}$ and $47^{\text {th }}$ floor in the longitudinal direction (X1). The top, middle and bottom panels in Figure 8 are shown the chi-chi earthquake, Hengchun M7.0 earthquake, and Hengchun M6.9 earthquake, respectively.

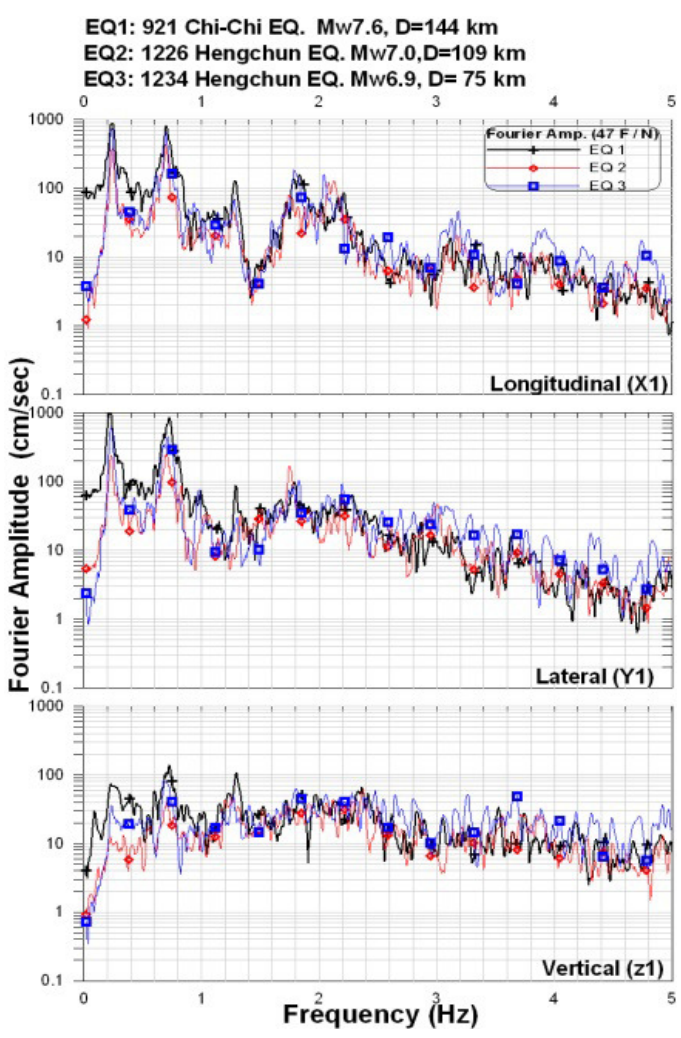

Figure 9. Fourier amplitude spectra of the three earthquakes in the $47^{\text {th }}$ floor. The top, middle and bottom panels in Figure 9 are shown the longitudinal, lateral, and vertical direction, respectively.

In order to determine if the frequency reduction in the earthquake was caused by soil-structure interaction, we calculated spectral ratio for the three earthquakes. The spectral ratio of the accelerations ( $47^{\text {th }}$ floor/ basement), together with the Fourier Amplitude Spectrum (FAS) of the $47^{\text {th }}$ floor and basement accelerations are shown in Figures 10 and 11 for the Hengchun M7.0 earthquake in the longitudinal and transverse directions, respectively. It is noted that the peaks of the $47^{\text {th }}$ floor FAS and the spectral ratio appear to coincide with each other from the records of 1226 Hengchun earthquake doublet, suggesting that there is no significant SSI effects in both the longitudinal and transverse directions. 


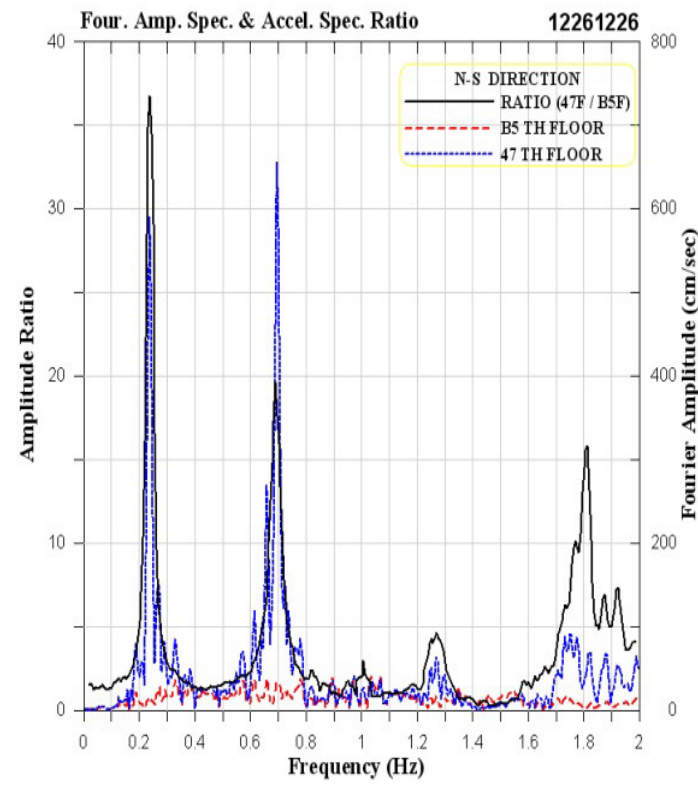

Figure 10. Fourier amplitude spectra of acceleration and spectral ratio of accelerations of $47^{\text {th }}$ floor and foundation of KBA0 in the longitudinal (north-south) direction for the Hengchun M7.0 earthquake.

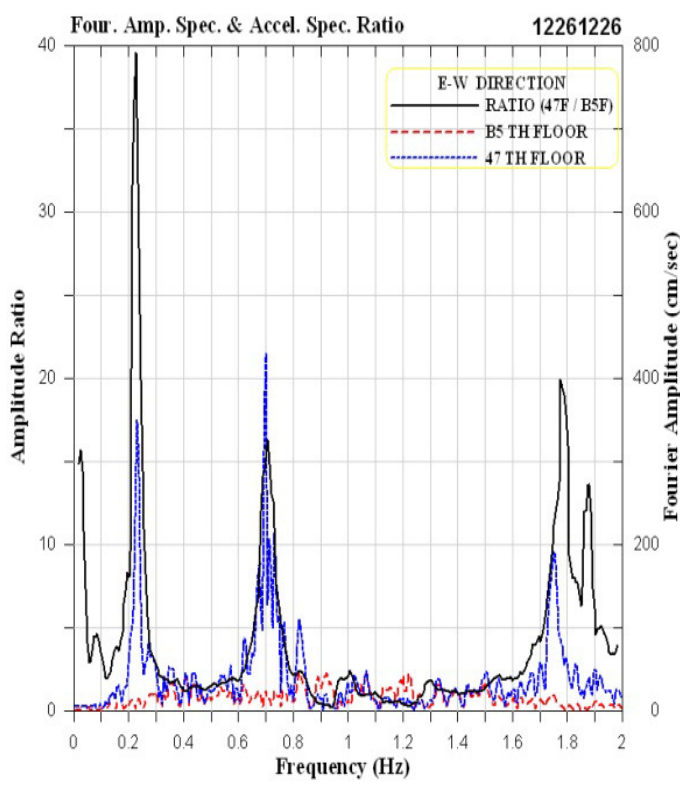

Figure 11. Fourier amplitude spectra of acceleration and spectral ratio of accelerations of $47^{\text {th }}$ floor and foundation of KBA0 in the transverse (east-west) direction for the Hengchun M7.0 earthquake.

\section{Conclusion}

The present study investigates the dynamic characteristics of a 51-story high-rise building by the transfer function (TF) method as well as assesses the SSI effects. Based on above results and discussion, we can draw the following conclusions:

1. Based on the observed transfer functions from the records of the Chi-Chi earthquake, the natural frequencies of the $1^{\text {st }}, 2^{\text {nd }}, 3^{\text {rd }} 4^{\text {th }}$, and $5^{\text {th }}$ longitudinal modes of the KBA0 Building are found to be $0.238,0.697,1.284,1.834$ and $2.207 \mathrm{~Hz}$, respectively. Likewise, the corresponding results for the transverse component are $0.220,0.715,1.290,1.797$, and $2.293 \mathrm{~Hz}$, respectively. It is found that these frequencies conducted from the code formula are closer to those identified from actual data.

2. From the building array with 26-channel accelerograms recorded from the three earthquakes, the acceleration amplification of seismic excitation on the 47 storey of KBA0 building is 4.24 , in the horizontal component, from the Chi-Chi earthquake data greater than those of the 1226 Hengchun earthquake doublet with a value of 2.82 and 2.06 , respectively.

3. From the spectral ratio of the accelerations $(47 \mathrm{~F} /$ basement), along with the FAS of the 47 -story and basement accelerations for the 1226 Hengchun earthquake doublet Chi-Chi earthquake, it is noted that the peaks of the $47^{\text {th }}$ floor FAS and the spectral ratio seem to coincide with each other, suggesting that there is no significant SSI effects in both the longitudinal and transverse directions.

\section{Acknowledgement}

The author thanks the Central Weather Bureau of Taiwan, ROC for providing excellent seismic data for the present study. This research was supported by the Ministry of Science and Technology of the Republic of China under Grant No. MOST 104-2116-M-244-001. 


\section{References}

1. T.C. Shin and T.L. Teng, An overview of the 1999 Chi-Chi, Taiwan, Earthquake, Bull. Seis. Soc. Am., 91 (5), 895-913 (2001)

2. K.S. Liu and Y.B. Tsai, Observed natural frequencies, damping ratios and mode shapes of vibration of a 30-story building excited by a major earthquake and typhoon, Earthquake Spectra, 26 (2), 371-397 (2010)

3. A. Turan, S.D. Hinchberger, E. Naggar, and M. Hesham, Seismic soil-structure interaction in buildings on stiff clay with embedded basement stories, Canadian Geotechnical Journal, 50, 858873 (2013)

4. C.C. Spyrakos, I.A. Koutromanos, and Ch.A. Maniatakis, Seismic response of base-isolated buildings including soil-structure interaction, Soil Dynamics and Earthquake Engineering, 29, 658-668 (2009)

5. J.P. Stewart, G.L. Fenves, and R.B. Seed, Seismic soil-structure interaction in buildings. I: Analytical method, Journal of Geotechnical and Geoenvironmental Engineering, 125 (1), 26-37 (1999)

6. J.J. Johnson, Soil-structure interaction, In: W.F. Chen and C. Scawthorn, editors, Earthquake Engineering Handbook, Part 2, Boca Raton, FL: CRC Press (2003)

7. FEMA 450. NEHRP recommended provisions for seismic regulations for new buildings and other structures (2003 edition), Building Seismic Safety Council (BSSC), Washington DC, (2003)

8. J. Aviles and L.E. Perez-Rocha, Site effects and soil-structure interaction in the Valley of Mexico, Journal of Soil Dynamics and Earthquake Engineering, 17, 29-39 (1997)

9. C.B. Crouse and J.C. Ramirez, Soil-structure interaction and site response at the Jensen Filtration Plant during the 1994 Northridge, California, mainshock and aftershocks, Bull. Seis. Soc. Am., 93 (2), 546-556 ( 2003)

10. ATC, Guidelines for Using Strong-Motion Data and Shakemaps in Postearthquake Response, ATC-54 Report, Applied Technology Council,Redwood City, California, (2005)

11. J.F. Clinton and T.H. Heaton, Is there a linear building transfer function for small excitation? EOS Trans. Am. Geophys. Union 84 _46_, Fall Meet. Suppl., Abstract, S51E-0102 (2003)

12. D.A. Foutch, The vibrational characteristics of a twelve-storey steel frame building, Earthquake Eng. Struct. Dyn., 6, 265-294 (1978)

13. M.D. Kohler, P.M. Davis, and E. Safak, Earthquake and ambient vibration monitoring of the steel-frame UCLA factor building., Earthquake Spectra, 21, 1-22 (2005)

14. Y. Li and S.T. Mau., Learning from recorded earthquake motion of buildings, Journal of Structural Engineering, 123, 62-69 (1997)

15. D. Skolnik, Y. Lei, E. Yu, and J.W. Wallace, Identification, model updating, and response prediction of a 15-story steel frame building, Earthquake Spectra, 22, 781-802 (2006)

16. M.D. Trifunac, Comparisons between ambient and forced vibration experiments, Earthquake Eng. Struct. Dyn., 1, 133-150 (1972)

17. E. Yu, D. Skolnik, D.H. Whang, and J.W. Wallace, Forced vibration testing of a vour-story reinforced concrete building utilizing the nees@ucla mobile field laboratory, Earthquake Spectra, 24, 969-995 (2008)

18. K.S. Liu, T.C. Shin, and Y.B. Tsai, A free field strong motion network in Taiwan: TSMIP, TAO, 10 (2), 377-396 (1999)

19. C.H. Loh and H.M. Lin, Application of off-line and on-line identification techniques to building seismic response data, Earthquake Engineering and Structural Dynamics, 25, 269-290 (1996)

20. G.W. Housner, Design spectrum, In Earthquake Engineering, (R. L. Weigel, Ed.), Prentice-Hall, Englewood Cliffs, New Jersey (1970)

21. G.H. McVerry, Structural identification in the frequency domain from earthquake records, Earthquake Engineering and Structural Dynamics, 8, 161-180 (1980)

22. P.C. Jennings, An introduction to the earthquake response of structures, In International Handbook of Earthquake and Engineering Seismology, (William Lee, Ed.), Academic Press, (2002) 
23. E. Safak, Detection and identification of soil-structure interaction in buildings from vibration recordings, J. Struct. Eng., 121, 899-906 (1995)

24. Y. Li and S.T. Mau., Anatomy of the loma prieta earthquake records of two steel buildings using mimo system identification, Proc., Conf. Engrg. Mech., ASCE, New York, 689-693 (1992)

25. K.C. Tsai, C.H. Loh, C.H. Yeh, and C.M. Su, Design examples and the recommended modifications on the tentative seismic force provisions for building structures in Taiwan, Architecture \& Building Institute, Ministry of Interior Research Project Report, Taipei (2001) 